\title{
Gilda Santos, Luci Ruas, Teresa Cristina Cerdeira (Orgs.). Sena e Sophia: centenários. Rio de Janeiro: Bazar do Tempo, 2020
}

\author{
Gabriela Silva*
}

Assim os melhores nos escrevem do princípio do mundo ${ }^{1}$

O ano de 2019 foi particularmente importante para a história, a cultura e a literatura portuguesa: comemorou-se o centenário do nascimento de Jorge de Sena e Sophia de Mello Breyner Andresen. Personalidades significativas, foram poetas, ficcionistas e críticos, pensaram o seu tempo a partir de um olhar crítico e esperançoso alinhado ao desejo de liberdade e justiça. Sujeitos de uma história marcada pela ditadura que controlou Portugal por quarenta anos, Sena e Sophia estabeleceram laços afetivos e construíram um imaginário literário alicerçado no exercício ético.

O evento "Sena e Sophia: centenários", organizado pelo Centro de Estudos do Real Gabinete Português de Leitura e a Universidade Federal do Rio de Janeiro, através da Cátedra Jorge de Sena, promoveu em setembro de 2019, no Rio de Janeiro o encontro de pesquisadores, professores, poetas e estudiosos da obra de Sena e Sophia. As palestras e conferências foram reunidas no livro Sena \& Sophia: centenários, organizado por Gilda Santos, Luci Ruas e Teresa Cristina Cerdeira. Publicado pela editora Bazar do Tempo, em 2020, com o apoio da Fundação Calouste Gulbenkian, o livro apresenta os textos dos conferencistas. O volume é composto de quatro partes distintas e complementares: Átrio: "em redor da mesa"; Sena: "capitão de tempestades"; Sophia: "no esplendor da maresia" e Sena \& Sophia \& outras vozes: "cartas poemas e notícias".

O prefácio de Teresa Cristina Cerdeira, "Celebrar Sena \& Sophia" apresentanos a obra de maneira significativa, compondo um panorama da biografia e da relevância dos escritores para a literatura portuguesa e ocidental, no século XX. "Ousamos defender que suas experiências de vida, seu investimento numa poesia que não deixa nunca de acenar para o tempo e a cumplicidade que desde muito

Doutora em Teoria da Literatura, professora-visitante na Universidade Federal de Lavras, MG, Brasil. E-mail: srtagabi@gmail.com.

1 Verso do poema "Lendo a correspondência entre Sophia de Mello Breyner e Jorge de Sena" de Luís Filipe Castro Mendes (2020, p. 28). 
cedo os uniu fazem dessa coincidência uma referência a não desprezar" (CERDEIRA, 2020, p. 9), diz-nos ao enunciar as motivações do evento e da publicação da obra. Evoca, para tanto, a amizade entre os poetas, marcada pela distância imposta pela ditadura . O prefácio abrange as partes que constituem a obra e coloca os temas de cada uma, evidenciando a variedade das leituras reunidas.

Somos convidados ao reino das palavras e das imagens de Sena e Sophia no texto de Luís Filipe Castro Mendes, no Átrio: "em redor da mesa", "Sena e Sophia: escrever no princípio do mundo". Apresenta-nos uma leitura das aproximações estéticas e temáticas entre Jorge de Sena e Sophia de Mello Breyner Andresen: a construção do poema, o significado do fazer poético e a liberdade, desejo de ambos. O texto encerra com poemas inéditos do autor dedicados aos homenageados, entre eles "Lendo a correspondência entre Sophia de Mello Breyner e Jorge de Sena", que nos mostra a clareza poética de Castro Mendes quanto à viva herança dos poetas.

Ao sairmos do Átrio, de arquitetura memorialística e poética, entramos nas divisões da obra, Sena: "capitão de tempestades", dedicada às vertentes literária e crítica, como também de tradutor e antologizador de Sena. Compreende textos de pesquisadores e estudiosos a partir de singulares perspectivas da produção do intelectual. Em "Jorge de Sena e seus sonetos: ainda que não" Annie Gisele Fernandes apresenta-nos uma leitura da escrita do soneto por Sena, revisitando a história da forma poética, a recusa do lugar comum, tanto dos modelos de composição quanto aos temas.

"Pensar a experiência contemporânea: o contributo de Maquiavel e outros estudos de Jorge de Sena" de Antonio Pedro Pita incide sobre a produção ensaística de Sena, especificamente a respeito de Maquiavel e outros estudos, que apresenta interpretações e estudos acerca de personalidades e ideias. Horácio Costa, em "O prodigioso físico do físico prodigioso", no início de sua leitura coloca ao leitor a natureza da sua proposta ou hermenêutica a partir de $O$ físico prodigioso: perceber a representação do corpo e do desejo masculino em Jorge de Sena: "a) junta retalhos de leituras e memórias de retalhos de leituras ao fio de décadas, tão frequentemente alimentadas enquanto memórias b) envolvem o meu corpo e um seu incômodo" (CosTA, 2020, p. 51).

Ida Alves, oferece-nos uma relevante perspectiva da obra ensaística de Jorge de Sena, salientando em seu texto "Jorge de Sena: um leitor da cultura brasileira", a importância da voz, força do pensamento e a contribuição imensa para a cultura de língua portuguesa, em sua criação estética ou crítica. Revisita a relação de Jorge de Sena com o Brasil, o exílio e a docência. Ida Alves ainda nos relembra da publicação de Estudos de cultura e literatura brasileira, publicado por Mécia de Sena, viúva de Jorge, em 1988, dez anos após a morte do escritor. Destacam-se as palavras de Ida Alves sobre a relevância dos estudos senianos, ao analisar e discutir a obra de escritores e intelectuais como Machado de Assis, Euclides da Cunha, Cecília Meireles, Manuel Bandeira entre outros. 
A repercussão da morte de Sena, é abordada em "Fazem cá um barulho com a morte do gajo!":Jorge de Sena na imprensa portuguesa", de Inês Espada Vieira. O texto é uma recolha e análise da repercussão na imprensa portuguesa procurando perceber que aspectos foram destacados no material publicado sobre a morte do autor. Fragmento da investigação em curso sobre a presença de Jorge de Sena no pós-25 de abril de 1974, o texto também apresenta os nomes de intelectuais que concederam depoimentos sobre Sena para diversos jornais na época .

"Questão da crítica literária no discurso de Jorge de Sena", de José Cândido de Oliveira Martins é uma abordagem do lugar da crítica na obra seniana. De acordo com o autor, Jorge de Sena proporcionou através da sua produção crítica abundantes reflexões dispersas, "quer sobre a natureza e o papel da crítica literária, quer mesmo sobre uma tipologia da crítica, apontando caminhos e denunciando vícios" (MARTins, 2020, p. 84). Por sua vez, a vertente de tradutor e organizador de antologias é o cerne de "Tradução e talento individual: Jorge de Sena tradutor e antologizador" de Joana Meirim, que apresenta o trabalho de tradutor realizado por Sena, para quem traduzir era também interpretar. A autora destaca os textos sobre tradução do escritor, entre eles, "Forma, conteúdo e tradução", publicado em 1974.

"Jorge de Sena e as cores da liberdade", de José Vaz de Carvalho parte do tema da liberdade na poética seniana, indicando elementos simbólicos e metafóricos associados a Portugal e suas imagens. Ainda sobre a poesia, Lucas Laurentino, em "Um jogo demoníaco" mostra-nos a atitude experimental de Sena, onde é preciso aceitar o convite do jogo poético para entendermos o sentido do poema. Luciana Salles, apresenta a construção da identidade na obra de Sena, em "Dos olhos de Artemidoro: reflexo e reflexão em Jorge de Sena". O ensaio incide na leitura do exercício autobiográfico percebido pela autora, principalmente na obra Metamorfoses.

Com evidente e provocativo viés irônico e político, Luis Maffei trata do erotismo na poética de Sena e na abordagem das imagens eróticas e sua banalização no atual contexto político brasileiro. O texto "Golden Shower segundo Jorge de Sena: diálogo místico" e "Filmes pornográficos para o Brasil de hoje" é uma revisitação do sentido de erótico em Sena e do paradigmático uso do corpo na arte, imagem amorosa e política.

A ficção de Jorge de Sena é contemplada por Marcelo Pacheco Soares no ensaio "O natal, a alquimia, o tempo e o espírito". A partir da obra Novas andanças do demônio, Soares estabelece relações simbólicas no conto "O urso, a pantufa, o quadro e o general". Também Margarida Braga Neves propõe interessantes relações com a significação da casa nos contos de Jorge de Sena. "Casa e casas nalguma ficção de Jorge de Sena" tem como corpus de análise As andanças do demônio, Novas andanças do demônio e Antigas e novas andanças do demônio. Espaço interno e externo são pensados tendo em vista a casa como "lugar de evolução e transformação, espaço de metamorfoses profundas que instauram um percurso ascendente"(Neves, 2020, p. 184). 
A presença da música na obra de Jorge de Sena são o ponto fulcral de "O 'pickup' de Jorge de Sena: sobre o suporte material da Arte de música" tratado por Rui Vieira Nery. As premissas estabelecidas identificam um Sena poeta, crítico, pedagogo e o musicólogo, manifestação em que se faz evidente o sentimento de Sena em relação à música: uma declaração de amor. Bach, Händel, Scarlatti, Haydn, o Mozart final, Beethoven, Schumann, o Liszt da velhice, Wagner, Brahms, Smetana, Mussorgsky, Mahler, Debussy, Satie, Bartók, Schönberg estão nos escritos de Sena, consagrando a história da música.

Em“Non de trás para a frente é non: a negatividade em Jorge de Sena" Sabrina Sedlmayer vale-se do conceito de negatividade na lírica testemunhal e nos contos, em narrativas que encenam contradições éticas e políticas. Sena aproxima-se da atitude filosófica dos gregos ao "inicialmente selecionar uma proposição para, posteriormente, negá-la com a sua crítica que a tudo enfrenta" (SEDLmaYer, 2020, p. 219). Outrossim, a ácida e voraz crítica seniana encontra espaço no texto de Silvio Renato Jorge, "Jorge de Sena: um olhar atento sobre o seu tempo". A partir da correspondência de Sophia e Sena, o autor apresenta a potência crítica de Sena em relação a sociedade portuguesa do seu tempo. Recorda que o escritor nunca se negou a correr riscos pela autenticidade da sua voz e ideias.

A segunda parte de Sena e Sophia: centenários é dedicada à Sophia de Mello Breyner Andresen. "Sophia: o esplendor da maresia" reúne ensaios que apresentam leituras originais da poeta. Entre essas apreciações está "A presença humana e a dimensão política em Contos exemplares” ensaio de Ângela Beatriz de Carvalho Faria. Encontramos uma abordagem das narrativas a partir das personagens metafóricas e da sensibilidade de Sophia quanto ao destino humano, expressões do seu sentido ético e político.

O feminino na poética andrensiana é o foco do ensaio "Figurações do feminino em Sophia, a poeta que amava os gregos", de Angela Maria Rodrigues Laguardia. O texto aponta para a aproximação com o mundo grego, rememora a formação da leitora Sophia, dos clássicos da antiguidade e todo o imaginário gerado na infância. Revisita ainda as artes poéticas e evidencia as figuras femininas míticas evocadas pela poeta: Eurydice, Penélope ou as Moiras. Carlos Mendes de Sousa em "Toda a vida vivida" trata da unidade que é busca constante na obra de Sophia: a experiência do tempo vivido, o tempo transcorrido e a vivência dos lugares. Também a memória que encontra seu espaço de manifestação na poesia e ficção da escritora. Por sua vez, Carolina Anglada escreve-nos em "Navegar, derivar: o dizer para ver de Sophia”, sobre a geografia portuguesa projetada nas imagens construídas pela poeta. Ainda, a partir do elemento da paisagem, Constance Von Krüger, em "Paisagem e palavra: Sophia e o silêncio" aponta-nos a potência da palavra em estabelecer relações com o silêncio das coisas na obra da escritora.

A presença de Sophia no Brasil, percorrendo as paisagens do país, é o tema de Eucanaã Ferraz em "No centro do reino de Ártemis A viagem de Sophia ao Brasil”. Impressões sobre a natureza, pessoas, mitos, nomes, sensações e sentimentos 
aparecem recortados e unidos pelo tecido do imaginário da poeta. Brasília, Rio de Janeiro, Recife e outros espaços, escritores e poéticas revisitadas emergem do texto de Eucanaã, numa espécie de materialização da presença de Sophia, erigida por afetos e leituras.

"No reino terrível da pureza, a prosa dispersa de Sophia" de Federico Bertolazzi analisa depoimentos, entrevistas, panfletos e intervenções variadas. Surgem nos escritos poetas, ficcionistas, críticos, amigos do mundo e da literatura: Jorge de Sena, Ruy Cinatti, Cecília Meireles, Maria Helena Vieira da Silva, João Cabral de Melo Neto. Bertolazzi propõe uma revisitação afetiva ao imaginário da poeta.

A produção para o público infantil é o objeto de atenção de Luci Ruas em "Entre flores e festa noturna, a busca da unidade em O rapaz de bronze". Ruas discorre sobre os conceitos de ético e estético no texto de Sophia. Ao descrever sua percepção da obra, aponta-nos uma harmonia no discurso do maravilhoso e na sua busca pela justeza de caráter, pela limpidez dos sentimentos e engendra a possibilidade do encantamento. Morte e memória constroem o tecido de "Sophia: tempo e memória", ensaio de Maria Elizabeth Graça de Vasconcelos, que aborda a prosa de Sophia, desde um viés filosófico das construções que se alinham à finitude e à lembrança.

A experiência lírica encerra as leituras da poética de Sophia em ensaios de grande potência ao se direcionarem para a criação das imagens e da vivência da poesia. "Atenta como uma antena: a invocação à Musa e a poética da escuta de Sophia”, de Maria Silva Prado Lessa, trata do conceito de poesia. Parte do poema Musa, de Livro sexto, para analisar o conceito da musa evocada. Roberto Bezerra de Menezes debruça-se sobre a escrita do soneto em "Desenhar a linha dos teus flancos: Sophia e o soneto", resgata Sá de Miranda, Camões, Antero de Quental e Florbela Espanca, poetas consagrados na arte do soneto para buscar a essência do exercício poético em Sophia. Por fim, Vilma Arêas em "Sophia - os pequenos pássaros da interpretação" oferece-nos uma leitura da experiência lírica da poeta. Refere-se à força que emerge das suas criações, identifica linhas mestras nas artes poéticas e as relações entre o fazer, o ser e o dizer. Constitui-se assim, um amplo espectro da poética andrensiana.

A última parte "Sena \& Sophia \& outras vozes: cartas, poemas e notícias" é composto por ensaios que apresentam leituras e relações entre os poetas e seus contemporâneos. Ana Luísa Amaral inicia com "Entre-cartas: paisagens com poemas, filhos, dois mares e liberdade ao fundo" ensaio memorialístico e afetivo, onde se articulam as principais características de Sena e de Sophia: a justeza de caráter, a pureza da poesia como espaço do espírito e da epifania. Figuras constituintes do imaginário poético e afetivo de Amaral, "meu Sena" e "minha Sophia", como designa a autora, são recordados pela obra abrangente e rica de imagens, metáforas e sobretudo, humanidade. "Sobre esta praia: a vida da poesia, Jorge de Sena e Gastão Cruz e uma nona meditação à beira do pacífico", de António Carlos Cortez, é uma aproximação entre Jorge de Sena e Gastão Cruz a partir dos conceitos de 
contemplação e o alinhamento entre as duas poéticas através da meditação e da experiência contemplativa do mundo.

Os imaginários de Sophia de Mello Breyner Andresen e Cecília Meireles são objetos de atenção de Jorge Fernandes da Silveira em "Capítulo sexto: Sophia e Cecília em companhia da biógrafa e da fadista no canto do conto". Silveira coloca que é o "texto literário uma biografia do seu tempo, oceânicas, Sophia e Cecília são biógrafas dos novecentos" (Silveira, 2020, p. 420), indicando-nos o caminho que suas ideias irão percorrer pelo universo lírico das poetas.

A revisitação de imaginários e aproximações são, do mesmo modo, o tema de Jorge Vicente Valentim em "Natália Correia e Jorge de Sena, um diálogo (im)provável(?)”, ensaio que propõe uma correspondência imaginária entre suas ideias e poéticas. As similaridades iniciam, de acordo com Valentim, na biografia dos poetas: "distintas experiências de criação literária, além, é claro, de verem boa parte de suas obras sofrer uma forte perseguição e censura por parte do Estado Novo Salazarista, em virtude do combate e da luta pela liberdade de expressão nesse contexto" (VALENTim, 2020, p. 426).

A correspondência entre Sena e Sophia, inesgotável em suas múltiplas leituras é o elemento em torno do qual se desenvolve o ensaio de Maria Otilia Pereira Lage, "Discurso epistolar entre Jorge de Sena e Sophia". Diálogo construído através de afinidades e cumplicidades, a correspondência entre os poetas e amigos é profícua e repleta de intensas percepções sobre o mundo, a história e os homens. Constituem segundo a ensaísta "arquivo vivo de criação para uma aproximação abrangente, mais por dentro, aos dois escritores, universos literários e poéticos que marcam e inspiram a literatura portuguesa contemporânea" (LAGE, 202O, p. 456).

"O surrealismo será aquilo que nossa atitude ditar", de Mônica Simas é uma leitura da relação de Jorge de Sena com o surrealismo, na aproximação com os críticos Adolfo Casais Monteiro e José-Augusto França e na crítica sobre Antonio Pedro. O texto é uma revisitação da polêmica estabelecida a respeito do surrealismo em Portugal e da percepção de Jorge de Sena da poesia associada ao movimento. "Sophia e João Cabral no gume do poema", de Rafaela Cardeal é um exercício ensaístico sobre a amizade e a poética cabralina e andrensiana. Aponta-nos similaridades e aproximações, indicando uma cumplicidade não somente no campo semântico e sonoro, mas no modo de ver os homens do seu tempo.

O diálogo epistolar entre Sena e Sophia, levado ao ecrã por Rita Azedo Gomes em Correspondências, filme de 2016 é o tema de "A correspondência entre Sena e Sophia e o diálogo com o cinema da poesia de Rita Azevedo Gomes”. Rui Pedro Vau, apresenta-nos a construção poética do filme que procura mostrar um diálogo que se organiza através de imagens de um universo comum e rico em interpretações de símbolos e metáforas. A aproximação entre os imaginários e as poéticas de Sophia e Murilo Mendes é o tema de "Sophia \& Murilo Mendes: visões da Grécia", de 
Silvana Maria Pessôa de Oliveira, texto do qual emerge a imensa carga simbólica e mítica que se origina e se mantém viva nas construções líricas dos poetas.

A influência de Sophia na poesia do século XX e XXI é o mote do texto de Sofia de Sousa Silva, "A poetisa e sua mestra". A intertextualidade entre a poesia de Adília Lopes e Sophia torna-se evidente, não só nas epígrafes e citações, mas na construção dos sentimentos e das imagens nos escritos de Adília. A aproximação entre poéticas é, de modo similar, a motivação do texto "Jorge de Sena e Cecília Meireles: o poema-errância em (irresistível) contraste”, de Susana L. M. Antunes. Viagens, errâncias, percursos e a passagem por diversos ambientes e paisagens são abordados pela autora que compõe, em sua análise, possíveis intersecções e identificações entre as itinerâncias poéticas de Cecília e Sena.

Os textos que compõem o volume apresentam aspectos, leituras e visões das obras, biografias e personalidades de Jorge de Sena e Sophia de Mello Breyner Andresen. Os autores de cada ensaio evidenciam ao leitor sua especial atenção sobre determinado detalhe, intertextualidades, similaridades, entrelaçamentos sentimentais e imagéticos. Vozes críticas, potências que reverberaram palavras e indagações sobre a humanidade. Sena e Sophia são arcabouços de ideias, imagens, lirismo e sobretudo, do desejo de que todas as possibilidades que contemplem o mundo com justiça e beleza possam, de fato, se concretizar. Sena \& Sophia: centenários, é, por fim, a certeza de que essas poéticas são infinitas e múltiplas em suas singularidades.

\section{Referências}

Santos, Gilda; Ruas, Luci; Cerdeira, Teresa Cristina (Orgs). Sena e Sophia: centenários. Rio de Janeiro: Bazar do Tempo, 2020.

Recebido em 9 de junho de 2021.

Aprovado em 28 de junho de 2021. 